\title{
“ADIÓS RÍOS, ADIÓS FONTES": ROSALÍA DE CASTRO Y LOS GALLEGOS DE CUBA
}

\author{
Josefa Lago Graña
}

\begin{abstract}
RESUMEN
El artículo explora el tema de la masiva emigración gallega a Cuba a finales del siglo XIX y su tratamiento en la poesía de Rosalía de Castro (1837-1885), particularmente en sus dos colecciones escritas en lengua gallega: Cantares gallegos (1863) y Follas novas (1880), en las que la poeta denuncia la situación de abandono del campo gallego y el estado de pobreza extrema en que se encuentran los que quedan, mayoritariamente mujeres y niños.

Palabras clave: Rosalía de Castro, poesía, emigración, Galicia, Cuba.
\end{abstract}

\begin{abstract}
The article explores the theme of the massive migration of Galician naturals to Cuba near the end of the $19^{\text {th }}$ century and its treatment in Rosalía de Castro's poetry, particularly in her two collections written in Galician language: Cantares gallegos (1863) and Follas novas (1880), in which the poet states her denunciation of the state of abandonment of the Galician countryside and the poverty suffered by those left behind, mainly women and children.
\end{abstract}

Key words: Rosalía de Castro, poetry, migration, Galicia, Cuba.

En 1861, un periódico madrileño, El Museo Universal, publicó un poema que cambiaría el panorama literario de la remota esquina del noroeste español llamada Galicia. El poema iba firmado por una joven de 25 años llamada Rosalía de Castro y estaba escrito en una lengua que no se había usado en poesía escrita en más de 500 años (desde las Cantigas de Santa María en el siglo XIV), una lengua desdeñada como dialecto, hablado sólo por los más pobres

Josefa Lago Graña. Profesora de Estudios Hispánicos. Departamento de Lenguas Extranjeras y Literatura. University of Puget Sound.

Correo electrónico: jlago@pugetsound.edu

Recepción: 9- 1- 2010

Aceptación: 8- 2- 2010 
e ignorantes campesinos gallegos. El poema adopta la voz de un hombre que se despide de su casa, de su pueblo, de su esposa y de su patria, al embarcarse rumbo a América, sabiendo que es posible que nunca regrese. Con esta composición, se inicia la denuncia política de una situación que había comenzado de forma masiva en 1853 y que continuará hasta bien entrado el siglo XX. Ese año fue el peor de una serie (1852-55), ya que lluvias torrenciales, heladas y plagas afectaron las cosechas gravemente y produjeron una grave hambruna. Ese mismo año el gobierno español despenalizó la emigración, creando un movimiento masivo a América en la segunda mitad del siglo XIX. Además de esta emigración aprobada por el gobierno, existía un movimiento paralelo de emigrantes ilegales, que salían del país para escapar el reclutamiento forzado y el pago de impuestos. A estos factores hay que añadir otro, documentado por Hernández Borge:

\begin{abstract}
A estas circunstancias, así como al aislamiento, a las malas comunicaciones, al bajo nivel educativo o al deseo de eludir el servicio militar, hay que unir una propaganda ejercida por las agencias de emigración por todas las aldeas y los estímulos que los países del otro lado del Océano ofrecían a los que llegaban a ellos ante su imperiosa necesidad de mano de obra. (Hernández Borge 1986: 46)
\end{abstract}

Estos movimientos migratorios tendrán graves consecuencias en el crecimiento demográfico de Galicia, que en los informes del censo de la segunda mitad del siglo XIX muestra un estancamiento demográfico causado por el desequilibrio entre el número de mujeres y el de hombres y por un bajísimo número de nacimientos. Esto se explica porque la mayoría de los emigrantes (tanto legales como ilegales) son hombres entre 18 y 35 años. Se estima que el número de emigrantes que salen -y no vuelven- de Galicia entre 1860 y 1900 es de 340.000, es decir, una quinta parte (1/5) de la población (Hernández Borge 1986: 48).

Cuando el poema, antes citado, aparece en 1861, Rosalía Castro de Murguía (nombre con que la poeta pasaría a conocerse tras su matrimonio con el historiador y escritor Manuel Murguía) ya había publicado una pequeña colección de poemas, La flor (1857), y frecuentaba las veladas políticas y literarias de Madrid y de su Santiago de Compostela natal. Tanto ella como sus contemporáneos intelectuales y amigos son el primer grupo con ideología política claramente separatista que se consolidan en el primer movimiento que se puede llamar "galleguista". Entre estos se destacan, además de su esposo, los también poetas Eduardo Pondal, Aurelio Aguirre y Manuel Curros Enríquez. Catherine Davies destaca el papel crucial de Rosalía en el desarrollo del nacionalismo gallego:

\footnotetext{
She and her husband were associated with the progressive Left, supported the revolutions of 1854 and 1868 , and worked toward the promotion of a distinctive Galician cultural identity. Once she was married to Murguía (1858), who (like most Galician progressives) did not speak the Galician language, Castro assumed a unique position in the developing nationalist movement. Not only had she spoken Galician since birth (she was brought up among peasants), but she was also educated and could write poetry. (Davies, 2001: 177)
}

El desarrollo de la autonomía política y cultural de Galicia se hizo evidente en las revueltas de la década de 1840, siendo la más famosa la que terminó en la batalla de Cacheiras en 1846, con los rebeldes derrotados por las tropas enviadas desde Madrid y después fusilados ante el pelotón. Víctima también de la represión fue el "banquete de Conxo" en 1856, organizado por Santiago Aguirre y Eduardo Pondal, ambos escritores y buenos amigos de Rosalía. Al mismo tiempo, continuaban los esfuerzos para desarrollar el uso público y oficial del gallego, que durante siglos había quedado relegado al ámbito privado y en zonas rurales. En 1853, se publica el A gaita gallega, de Xosé Manuel Pintos, el primer libro en gallego tras 
los "siglos oscuros". La celebración de los Juegos Florales de Galicia en 1861, con su fuerte reivindicación del uso de la lengua gallega, anima al esposo y los amigos de Rosalía a pedirle a la poeta que use el gallego en sus composiciones como arma política. En 1872, se produjo una revuelta popular en Ferrol a favor de la República que fue condenada por Pi Y Margall, creando esto una brecha entre los federalistas españoles y los gallegos. Por fin, se declara la Primera República en 1873, y simultáneamente el Partido Republicano de Galicia, con el objetivo de reclamar el autogobierno y la autonomía.

Debido a estas excepcionales circunstancias, Rosalía de Castro es la primera poeta en expresar una identidad nacional en lengua gallega. Es también la primera en discutir el problema de la emigración gallega en la literatura desde sus composiciones más tempranas. Sin embargo, debe ser notada la participación de Manuel Murguía, el esposo de Rosalía, en la vida profesional de su esposa, lo cual Carballo Calero documenta ampliamente y prueba que Murguía envió el manuscrito de Cantares gallegos a la imprenta de Xoán Compañel en Vigo sin el conocimiento de la autora en 1863. Años después, en 1872, se publicó una segunda edición del volumen, corregido y editado por la poeta. Esa versión es la que se ha usado desde entonces para ediciones sucesivas.

Los poemas de Cantares gallegos usan variaciones de canciones folklóricas que se repiten como refrán al principio o al final de los poemas y adopta motivos populares y costumbristas, centrándose en la alabanza de la tierra, la gente y las costumbres, lo cual cimenta la fama de Rosalía como representante del Romanticismo tardío español, junto con Gustavo Adolfo Bécquer. La estructura básica de la colección consta de un poema introductorio en que una joven expresa su intención de cantar canciones populares de la tierra tal como le han pedido que haga. Esta composición sirve de marco narrativo para el resto de los poemas de la colección y la joven vuelve para cerrar la serie en un poema donde dice que ha cantado todo lo que sabe.

A pesar del color costumbrista y de inspiración popular que domina la colección, uno de los temas recurrentes es la denuncia del mal tratamiento recibido por los trabajadores gallegos en Castilla y el desprecio hacia Galicia que la poeta percibe en el resto de España. El tema ya aparece en la dedicatoria del libro a Fernán Caballero (seudónimo de Cecilia Bohl de Faber), autora que según Rosalía merece alabanza "por haberse apartado algún tanto, en las cortas páginas en que se ocupó de Galicia, de las vulgares preocupaciones con que se pretende manchar mi país" (26). En el prólogo que le sigue, Rosalía se queja amargamente de las injustas críticas que sufre Galicia y su lengua, su gente y su paisaje en el resto de España. Rosalía concibe Cantares gallegos como elogio de la tierra gallega y su gente, pero también en defensa de éstos, para contrarrestar la mala opinión que percibe a su alrededor:

Mais he aquí que o mais triste nesta cuestión é a falsedade con que fora de aquí pintan así ós fillos de Galicia como a Galicia mesma, a quen xeneralmente xuzgan o mais despreciable e feio de España, cando acaso sea o mais fermoso e dino de alabanza. (28)

La denuncia del mal tratamiento que se les daba a los trabajadores gallegos en otras provincias españolas y el mal nombre asociado con la tierra gallega es consecuencia directa de la experiencia de la propia poeta durante su vida en Madrid. Este tema es tratado en detalle en poemas como el 17 "Airiños", el 23 "Castellana de Castilla" y el 28 "Castellanos de Castilla", y se corresponde a lo que María del Carmen Porrúa describe como el exilio intra-peninsular, que se contrasta con el otro tipo que Porrúa denomina el trans-oceánico (404), que también 
aparece en Cantares Gallegos y más tarde en Follas Novas de forma más amplia. En "Airiños" el yo poético le pide al viento que la devuelva a su tierra donde su padre y madre la esperan, ya que teme no poder vivir lejos de ellos:

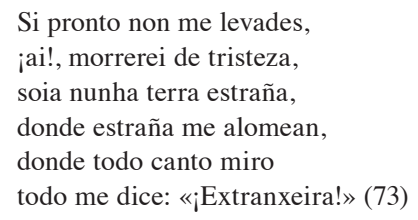

En "Castellana de Castilla", la voz poética habla directamente a una mujer "bonita e fidalga" pero también ingrata, hosca y soberbia en su tratamiento de aquellos que no pertenecen a su clase o a su patria. "Castellanos de Castilla" continúa el formato monológico, pero ahora la poeta no se dirige a un individuo, sino a toda la comunidad castellana, a los que considera responsables de las condiciones de vida y trabajo de sus compatriotas del norte, que van a Castilla cada año por la época de la siega y vuelven a Galicia agotados y maltratados:

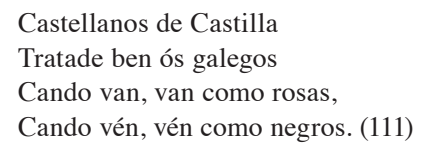

Estos poemas contienen un elemento autobiográfico, con un yo poético muy cercano a la experiencia de la propia Rosalía, quien en esa época vivía en Madrid por las obligaciones profesionales de su esposo Manuel Murguía, quien por aquel entonces trabajaba en capacidad de historiador en los archivos de Simancas y Madrid. Son poemas abiertamente políticos y adoptan un tono combativo que contrasta fuertemente con la mayoría de los poemas de la colección. Aquí hay una denuncia clara y fuerte no sólo de la actitud despectiva y hasta racista de los castellanos, sino también de la política centralista del gobierno de Madrid, por perpetuar la opresión de los trabajadores y mantener a Galicia en tales condiciones de pobreza que la única forma de sobrevivir es el trabajo de temporero y la emigración. Aunque Rosalía no conecta de forma explícita esta experiencia con el movimiento galleguista con ideología separatista y de autogobierno del que forma parte activa, la conexión sería obvia para cualquier gallego que leyera versos como los citados anteriormente.

En toda su obra poética, tanto en Cantares gallegos como más tarde en Follas novas (1880), Rosalía le canta a aquellos que deben abandonar hogar y nación, pero más aún a aquellos que quedan atrás, que con frecuencia son mujeres y niños. En ambas colecciones, el exilio transoceánico, particularmente a Cuba, es un tema central y un fenómeno que la poeta ya había percibido desde su inicio en 1853. Rosalía se dio cuenta muy pronto del gran impacto que este movimiento migratorio tendría en el desarrollo demográfico y cultural de Galicia. Porrúa menciona que en aquellos poemas en que el foco es la emigración trans-oceánica hay una denuncia de los abusos del gobierno como una de las razones que fuerzan a los gallegos a emigrar (406). El tono ligero y juguetón que domina otros poemas de la colección está ausente en éstos: 
La composición 15 "Adiós ríos, adiós fontes" ya había sido publicada de forma independiente en el periódico madrileño El Museo Universal. La versión incluida en la colección difiere de la versión más temprana en que incorpora un refrán en versos octosílabos al principio y al final de la composición para ajustarse al formato de la colección y para contribuir al tono folclórico. El poema adopta la voz del hombre que se despide del campo gallego, de su aldea y de su mujer, cuando está a punto de embarcarse en el vapor que lo llevará al otro lado del Atlántico:

\footnotetext{
Adiós ríos, adiós fontes,

Adiós regatos pequenos,

Adiós vista dos meus ollos

Non sei cando nos veremos (69)
}

Las primeras cinco estrofas son puramente descriptivas, mencionando todos los elementos del entorno natural de la voz poética: la huerta, la higuera, los prados, los ríos, los pinos, los pájaros, la casa, el molino, las campanas de la iglesia y los campos de maíz. La palabra "adiós" se repite cuatro veces en la primera estrofa y dos veces más al final de la quinta, poniendo en primer plano el momento doloroso de la partida. En las estrofas seis y siete, la descripción se convierte en acción: la palabra "deixo" se repite seis veces, poniendo énfasis en el distanciameiento y la separación, la desposesión y el abandono del que tiene que dejarlo todo atrás. La estrofa ocho es la más directa y la más abiertamente política, ya que expone las razones de la partida del pobre y desposeído y acusa al gobierno como agente de la desposesión de sus ciudadanos:

\footnotetext{
Mais son pobre e, mal pecado,

A miña terra no é miña,

Que hasta lle dan de prestado

A beira por que camiña

Ó que naceu desdichado. (70)
}

Las últimas dos estrofas incluyen la única referencia a una persona en todo el poema -aparte de la voz poética-: la esposa que se queda sóla en la aldea. También, dan una indicación del destino final al que se dirige el hombre, aunque el poema no es explícito. El hombre se despide junto al mar e implica la posibilidad de morir de tristeza en una tierra lejana. Está claro que Rosalía, incluso en esta fecha tan temprana, ya está comentando sobre la creciente emigración a Cuba, aunque aún no se refiere, como lo hará más tarde, a los efectos de esta emigración en Galicia y su gente. Este es un poema que captura a la perfección la "morriña" con que se identifica universalmente al gallego y no en vano se ha convertido en uno de los poemas más citados y recitados por gallegos en todo el mundo.

Otros tres poemas de la colección comparten el tema de la emigración trans-oceánica: el número 19 "Pasa río, pasa río" presenta la voz poética de la mujer que le habla al río y le pide que lleve sus lágrimas al mar y de ahí quizá lleguen a su amado en América. Por su parte, el número 24 "Queridiña dos meus ollos" adopta el formato de una carta que un soldado al servicio del rey en Cuba le manda a su mujer que lo espera en Galicia. En este poema, se respira un optimismo y un tono esperanzado ausente de las demás composiciones. Por último, el número 29 "A gaita gallega" es un poema largo dividido en cinco partes, y combina de nuevo el tema de la emigración con un ataque al gobierno central de Madrid, al cual culpa de la recesión económica de la región: 
I ¡ai! Como [nas naves] navegan

Os fillos das nosas costas

Con rumbo a América infanda

Que a morte con pan lles dona

Desnudos pedindo en vano

Á patria misericordia (116)

La metáfora que domina este poema es la de los niños huérfanos que lloran la ausencia de la madre, que por momentos es España, pero más frecuentemente Galicia. Estas dos imágenes femeninas se presentan como modelos opuestos: mientras que España es una madre orgullosa, fría, lejana y ausente que ignora las necesidades de sus hijos, Galicia, por su parte, es una madre llorosa, pobre y abandonada, que llena de pena debe dejar marchar a los hijos a los que no puede mantener:

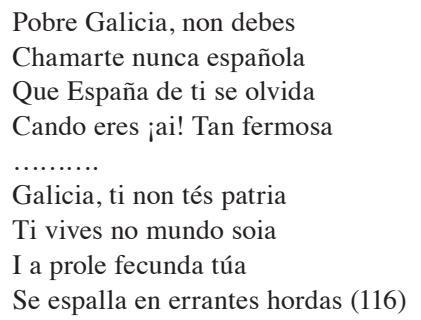

Aunque el impacto de esta colección no fue significante en Galicia y no convirtió a Rosalía en figura famosa en su tierra, el libro y su autora se hicieron muy populares en Cuba, gracias a los emigrantes gallegos, sobre todo los analfabetos, quienes, según Catherine Davies, se aprendían de memoria estos cantares modernos y a menudo los recitaban como himnos patrióticos (1986: 186). Los gallegos que van a Cuba en estos años se ven inmersos muy pronto en un ambiente social e intelectual que clama por la independencia. Los cubanos sufren las consecuencias de la política colonialista de España y se sienten limitados en el comercio por tarifas e impuestos dictados por el gobierno central de Madrid. Tanto Galicia como Cuba sufren formas de colonización española, discriminación social y pobreza, causada por la política centralista. La emigración gallega a Cuba está causada por dificultades económicas o para evitar el reclutamiento forzoso y los impuestos. Otros llegan a Cuba como soldados del rey para luchar contra los rebeldes cubanos que luchan en la primera guerra por la independencia de la isla, pero la falta de lealtad a España y la identificación con los rebeldes hace fácil el cambio de bando. Xosé Neira Vilas, en su libro Galegos que loitaron pola independencia de Cuba documenta los nombres de cientos de gallegos que pelearon por la independencia de Cuba en las filas mambises.

El movimiento migratorio a América continúa e incrementa durante las siguientes décadas. A nivel político ocurren muchos cambios a ambos lados del Atlántico en este tiempo: la revolución de 1868, la proclamación de la Primera República en 1873 en España y en Galicia, en ese mismo año, se da la creación del Partido Federal Gallego, que reclama autogobierno y un estado propio para Galicia. En Cuba, se declara la primera guerra por la independencia, encabezada por Carlos Manuel de Céspedes, en 1870. Ya para entonces la comunidad gallega en Cuba es más numerosa y su presencia en la vida intelectual de la isla, sobre todo de La Habana, está consolidada. En 1871, se crea la primera asociación de gallegos en Cuba: la "Sociedad de Beneficencia de los Naturales de Galicia en Habana". Es muy significante que Rosalía es nombrada socia honoraria de la asociación al año siguiente de su creación, una clara 
indicación de su popularidad en Cuba, particularmente a raíz de la publicación de la segunda edición de Cantares gallegos (1872) esta vez corregida y editada por la poeta.

El mismo Xoan Compañel, que imprimió la primera edición de CG, se fue a Cuba en 1873 y vivió en la Habana hasta su muerte en 1897. Otro gallego que tendrá gran impacto en el desarrollo del nacionalismo gallego en Cuba es un amigo personal de Compañel y de Murguía: Alexandre Chao, que después de fundar el diario vigués La Oliva, se va a Cuba en 1859. Allí funda la revista literaria El Ateneo, varios seminarios satíricos y el periódico La Legalidad. También funda la librería e imprenta La Propaganda Literaria, primero en La Habana, y luego abre una sucursal en Madrid, colocando como director de ésta a Murguía. En 1880, Chao edita el segundo poemario en gallego de Rosalía, Follas Novas, que sale con sello editorial de $L a$ Propaganda Literaria y se imprime en sus talleres de Madrid.

En esta década de los 70, se establecen varias revistas literarias en La Habana que tendrán como tema fundamental Galicia y los gallegos, tanto los de la península como los de la isla. El Eco de Galicia, el primer semanario bilingüe español/gallego de Cuba, es quizá el más relevante y el que gozó de más larga vida, con ediciones continuas por un período de 23 años. Fundada en 1878 por Waldo Alvarez Insúa, Neira Vilas la describe como "unha publicación exemplar, defensora dos intereses dos emigrantes e sensible ós aconteceres da Galicia territorial"' (1985: 13).

Jo Labanyi, en su estudio dedicado al género y la modernización en la novela realista española, se concentra en su introducción, titulada "Writing the Nation", en la articulación de la importancia de los textos realistas, en el proceso de construcción de la nación por medio de la escritura. Entre los factores que destaca como claves en este proceso, Labanyi menciona la prensa escrita, revistas, periódicos y compañías editoriales que tienen un papel clave en difundir las ideas nacionalistas y crear una comunidad virtual de lectores: "Any cultural form appealing to a nationwide mass public can be said to contribute to nation formation; nationalism is dependent on the existence of modern forms of mechanical mass production" (2000: 6). Esta 'comunidad imaginada' está unida, según Labanyi, por una ansiedad compartida que se sobrepone a creencias particulares, incorporando diferentes sectores de la población en un sistema cultural que todos comparten.

Al mismo tiempo que esta actividad literaria y periodística se desarrolla en Cuba, Rosalía ha estado escribiendo, pero no publica ninguna obra hasta 1880. Entonces, aparece su segundo poemario en gallego Follas Novas, y de nuevo la intervención de la Sociedad de Beneficencia es fundamental, a tal punto que Rosalía les dedica el libro: "Ós señores da xunta directiva é mais individuos que compoñen a sociedade de beneficencia dos naturales de Galicia na Habana" (22), firmando luego con su nombre y su título de socia honoraria de la Sociedad. Rosalía dedica esta "expresión de amor para a patria ausente" a "os meus paisanos na Habana" (22), añadiendo que

\footnotetext{
O día en que os fillos de Galicia levaban a cabo na Habana un dos seus gloriosos feitos; o día en que, entre o aplauso de todos, fundouse en tan lexana rexión a SDBDNDG, houbo quen quixo santificalo ó seu modo volvendo para a súa patria os ollos i o corazón, unido naquela obra de patriotismo o recordo dun libro que foi tamén o esaltado fruto de amor ó noso país. (21)
}

En el prólogo, titulado "Dúas palabras da autora”, Rosalía habla de forma directa, claramente política, con conciencia clara de la magnitud del problema de la emigración y las desastrosas consecuencias sociales y económicas para Galicia. Davies afirma que es gracias a Rosalía que el nacionalismo cultural gallego adquiere una dimensión de género: 
She put her literary talents to political ends through her husband's circle of friends, but she made her presence known to them in her feminist writings. The woman's perspective she adopted in her later work proved crucial for the engendering of Galician cultural nationalism. (Davies 2001: 177-78)

La preocupación por cuestiones de género es evidente en el prólogo de Follas novas en afirmaciones como "mais son muller, e ás mulleres, apenas si a propia femenina franqueza lle é permitido adiviñalas, sentilas pasar [as penas alleas]” (24). El prólogo contiene una condena abierta de las razones que causan el exilio de miles, así como de las consecuencias del reclutamiento y sus efectos sociales, sobre todo en lo que afecta a las mujeres gallegas:

\footnotetext{
A emigrazón i o Rei arrebátanlles [ás mulleres] de contino o amante, o irmán, o seu home, sostén da familia decote numerosa; e así, abandonadas, chorando o seu desamparo, pasan a amarga vida antre as incertidumbres da esperanza, a negrura da soidade i as angustias dunha perenne miseria. (27)
}

En contraste con la sencillez estructural de Cantares gallegos, Follas novas es una colección compleja, altamente estructurada y organizada temáticamente, con planteamientos desarrollados y profundamente elaborados. El tono grave y reposado de este volumen es quizá consecuencia de las circunstancias personales de Rosalía, quien llevaba 13 años sin tener presencia en el mundo editorial (desde la publicación de su novela El caballero de las botas azules en 1867), pero no abandonó nunca la escritura y de hecho había escrito muchos de los poemas de Follas novas diez años antes de que vieran la luz en 1880, según ella misma confiesa en el prólogo. Los poemas aparecen organizados en cinco secciones independientes: I. Vaguedás; II. Íntimas; III. Varia; IV. Da terra; V. Ás viúdas dos vivos e as viúdas dos mortos. La narrativa de la emigración es consistente y mucho más organizada aquí de lo que lo estaba en Cantares gallegos. La preocupación con la migración intra-peninsular está ausente de este texto, mientras que los efectos del exilio cubano se convierten en el foco principal de la quinta y última sección de la colección. Ricardo Carballo Calero concuerda que

\footnotetext{
En la sección titulada "As viudas dos vivos e as viudas dos mortos", aparece más entregada que nunca al empeño de expresar las tribulaciones que veía padecer a las gentes humildes que la rodeaban. Dicha sección constituye una epopeya popular fragmentaria en que se canta el dolor y la tragedia de la emigración, vistos desde los ojos de la mujer que permanece en el país del que el hombre se ha alejado (1963: 11)
}

El primer poema de esa sección quinta merece especial atención. Titulado “¡Pra a Habana!", el poema está dividido en cinco partes que paralelan el proceso migratorio, empezando con las preparaciones, las despedidas y las vicisitudes del viaje. También, aparece claramente identificado el lugar de destino, que en el volumen anterior solamente estaba implícito. La primera sección describe las dificultades económicas que causan la decisión para el viaje a ultramar, refiriéndose a un "ellos" anónimo que se apropia y vende todos los bienes (los bueyes, la vaca, el carro, la tierra, la comida y la manta) dejándolo literalmente con lo puesto ("deixárono soio/coa roupa vestida") de un campesino también anónimo y luego adopta de nuevo la voz de ese campesino (de forma similar a como lo había hecho en "adiós ríos") que se dirige a su esposa para explicarle las razones que causan su partida y despedirse de ella:

\footnotetext{
María, eu son mozo,

Pedir non me é dado;

Eu vou polo mundo

Para ver de ganalo.

Galicia está probe, i á Habana me vou ...

¡Adiós, adiós prendas

Do meu corazón! (167)
} 
Esa primera sección mantiene un tono optimista a pesar de lo negativo e injusto de la situación y el hombre mantiene la esperanza de poder triunfar en esta nueva empresa. La segunda sección presenta a un grupo de hombres de camino al puerto de La Coruña donde les espera el vapor, pero la descripción del futuro se vuelve oscura y se presiente un final trágico:

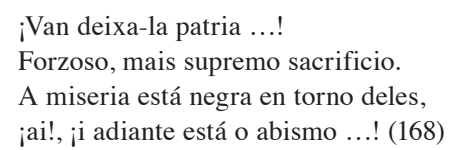

En la tercera sección, los hombres están ya a bordo del vapor y el tono se vuelve aún más oscuro, con la voz poética anticipando ya su muerte, bien en la ciudad de la Habana, bien en algún lugar perdido de la selva, identificando a Cuba con un cementerio, para volver luego los ojos, de forma consistente con la temática rosaliana, a las madres y esposas que los esperan del otro lado:

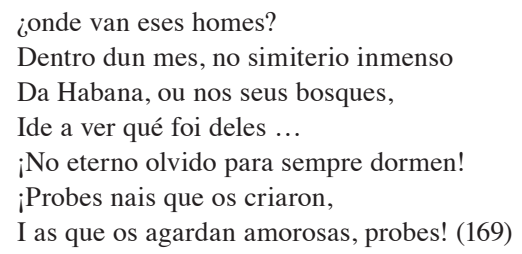

La cuarta sección cambia drásticamente el tono del poema y nos presenta las voces de los hombres, a punto ya de llegar a puerto, llenas de esperanza y de un sentimiento de solidaridad y unidad frente a lo desconocido, pero con una nota triste y tenebrosa al final, en la que el poeta contrasta las caras alegres de los hombres con el eco siniestro de las campanas de la iglesia que tocan a muerto:

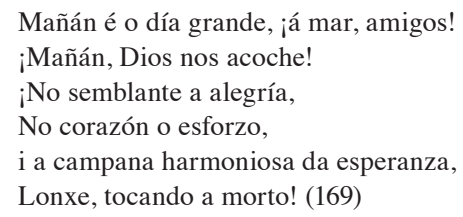

El último poema de esta sección funciona como un resumen de la situación y la poeta le habla directamente a Galicia, de nuevo personificada en la forma de madre abandonada. Las imágenes son perfectamente consistentes con las que ya aparecían en Cantares Gallegos, pero el mensaje aquí es directo y explícito:

Este vaise i aquél vaise,

E todos, todos se van.

Galicia, sin homes quedas

Que te poidan traballar.

Tes, en cambio, orfos e orfas

E campos de soledad

E nais que non teñen fillos

E fillos que non tén pais.

E tes corazóns que sufren

Longas ausencias mortás,

Viudas de vivos e mortos

Que ninguén consolará. (169-70) 
El resto de los poemas de esta sección vuelven los ojos a las mujeres que quedan en el campo gallego, sin hombre, solas y pobres, al cuidado de los hijos y del pedazo de tierra, si lo tienen. El poema “¡Terra a nosa!” (173) describe la pobreza física, pero también metafóricamente se refiere a la ausencia de los hombres que va a tener como consecuencia el estancamiento demográfico de la región, al citar el horno sin pan y el lugar sin leña para encender fuego. Aún hay una nota de esperanza en la mención de la llegada de la primavera que traerá las lluvias necesarias para una buena cosecha, que a su vez puede prevenir el hambre y por lo tanto la necesidad de emigrar. "Tecín soia a miña tea" (178) es una reflexión de una "viuda de un vivo" que expresa su tristeza y también su enojo sobre su situación y se lamenta de no saber qué ha pasado con su hombre, del que no ha tenido noticias. Por último, una breve composición indica, en versos cortos y tajantes, que las lluvias esperadas no llegaron en la primavera, sino a final de junio, lo que destruyó las cosechas, forzando otra vez a los campesinos a abandonar la tierra, perpetuando el ciclo migratorio que ya ha probado ser desastroso para Galicia:

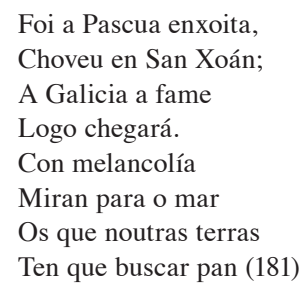

La popularidad de Rosalía se acrecienta considerablemente a raíz de la publicación de Follas novas, particularmente en Cuba. Sin embargo, la poeta vivirá aislada, pobre y enferma de cáncer en el campo gallego hasta su muerte en 1885 a los 48 años de edad. Davies describe un ejemplo sintomático de ese aislamiento: una carta que la poeta escribe a Waldo Álvarez Insúa para agradecerle la colecta en su honor entre lo emigrantes. Hasta ese momento, Rosalía nada sabía de esas actividades ni tampoco de las publicaciones cubanas en su honor. Davies añade que los únicos que en ese momento prestaban atención a la obra de Rosalía eran las comunidades en el exilio de Cuba y Argentina, y afirma que:

\section{Castro was admitted much later into the Spanish literary canon on the basis of her reputation as a popular Galician poet acquired in the former colonies, among the mostly male Galician diaspora. In complicated and seemingly disparate ways, therefore, the production and reception of her work was shaped almost entirely by national politics. (Davies 2001: 182)}

Con motivo de su enfermedad y luego su muerte, la Sociedad de Beneficencia tendrá de nuevo un papel fundamental en la vida de Rosalía y su familia. Desde el semanario El Eco de Galicia, Álvarez Insúa hace un llamado a la comunidad para establecer una colecta que ayude a Rosalía y Manuel Murguía en un momento de graves dificultades económicas para la pareja. En poco tiempo, reúnen cerca de 2.000 pesos en oro que envían inmediatamente a Galicia. Apenas año y medio después se recibe en Cuba la noticia de la muerte de la poeta. Las publicaciones gallegas dedican números especiales a este suceso, que también es recogido por la prensa cubana. Poco después, surge la idea de recolectar dinero para la construcción de un panteón que albergue los restos de la poeta. La empresa tiene éxito y se construye en Santiago el panteón donde reposan sus restos hasta el día de hoy.

En 1905, se crea la Academia Gallega en La Habana. Manuel Curros Enríquez sirve como primer presidente, y unos meses después, ese mismo año, por iniciativa de Murguía, 
se constituye la Academia en La Coruña. También en La Habana, en el Teatro Nacional, en 1907, se interpreta por primera vez el poema de Eduardo Pondal "Qué din os rumorosos" con música de Pascual Veiga, que pasará luego a convertirse en el Himno Gallego de forma oficial en 1913. La bandera gallega también fue "inventada" por emigrantes en Cuba, que adoptaron la bandera de la Comandancia de Marina de La Coruña como símbolo patrio, que luego se haría también oficial. Resulta claro que la comunidad gallega en Cuba no sólo sirve de apoyo y sostén al desarrollo del nacionalismo gallego, sino que ocupa un lugar destacado en la génesis de los símbolos de ese nacionalismo. Entre éstos, quizá el principal sea la obra de esta poeta gallega que nunca pisó la isla.

\section{Bibliografía}

AA.VV. 1986. Actas do Congreso internacional de estudios sobre Rosalía de Castro e o seu tempo. Santiago de Compostela: Consello da Cultura Galega, U. de Santiago de Compostela.

Carballo Calero, Ricardo. 1963. "Introducción”. Cantares gallegos. Salamanca: Anaya.

Castro de Murguía, Rosalía. 1963. Cantares gallegos. Salamanca: Anaya.

1880. Follas Novas. Vigo: Galaxia.

Davies, Catherine. 2001. "Rosalía de Castro: Cultural Isolation in a Colonial Context". En: Vollendorf, Lisa (ed.), 176-97.

Hernández Borge, Julio. 1986. "Notas sobre la emigración gallega en la segunda mitad del siglo XIX”. En: AA.VV., 45-55.

Labanyi, Jo. 2000. Gender and Modernization in the Spanish Realist Novel. Oxford: Oxford UP.

Neira Vilas, Xosé. 1985. A prensa galega en Cuba. A Coruña: Ediciós do Castro.

1992. Rosalía de Castro e Cuba. A Coruña: Ediciós do Castro.

2000. Manuel Murguía e os Galegos de Cuba. A Coruña: Ediciós do Castro.

Porrúa, María del Carmen. 1986. "El tema de la emigración en la poesía de Rosalía de Castro y su proyección en dos poetas gallegos". En: AA.VV, 399-410.

Vollendorf, Lisa (ed.). 2001. Recovering Spain's Feminist Tradition. New York: Modern Language Association of America. 